\title{
RIP1 kinase activity-dependent roles in embryonic development of Fadd-deficient mice
}

\author{
Yongbo Liu ${ }^{1,7}$, Cunxian Fan ${ }^{1,7}$, Yifan Zhang ${ }^{2}$, Xianjun Yu ${ }^{1,3}$, Xiaoxia Wu ${ }^{1}$, Xixi Zhang ${ }^{1}$, Qun Zhao ${ }^{1}$, Haiwei Zhang ${ }^{1}$, Qun Xie ${ }^{1,4}$, Ming Li ${ }^{1}$, \\ Xiaoming $\mathrm{Li}^{1}$, Qiurong Ding ${ }^{1}$, Hao Ying ${ }^{5}$, Dali Li ${ }^{6}$ and Haibing Zhang ${ }^{\star, 1}$
}

RIP1 is an essential regulator of TNF-induced signaling complexes mediating NF- $\kappa$ B activation, apoptosis and necroptosis. Loss of Rip1 rescues the embryonic lethality of Fadd or Caspase-8-deficient mice, even though the double knockout mice die shortly after birth like Rip1-deficient mice. Recent studies demonstrated that mice expressing RIP1 kinase-dead mutants developed normally and resisted necroptotic stimuli in vitro and in vivo. However, the impact of RIP1 kinase activity on $\mathrm{Fadd}^{-/}$embryonic development remains unknown. Here, we engineered two RIP1 kinase inactive mutant mouse lines, a Rip ${ }^{K 45 A / K 45 A}$ mouse line as previously reported and a novel Rip $1^{\Delta / \Delta}$ mouse line with an altered P-loop in the kinase domain. While RIP1 ${ }^{\mathrm{K} 45 \mathrm{~A}}$ could not rescue the embryonic lethality of Fadd-deficient mice at E11.5, RIP1 ${ }^{\Delta}$ rescued lethality of Fadd ${ }^{-1}$ mice at E11.5 and Fadd ${ }^{-/-}$Rip $^{{ }^{\Delta / \Delta}}$ mice eventually died at E16.5 due to excessive death of fetal liver cells and unregulated inflammation. Under necropotosis-inducing conditions, comparing to Rip $1^{K 45 A / K 45 A}$ cells, Rip $1^{4 / \Delta}$ cells displayed reduced phosphorylation and oligomerization of RIP3 and MLKL, which lead to increased cell viability. Thus, our study provides genetic evidence that different kinase inactive mutations have distinct impacts on the embryogenesis of Fadd-deficient mice, which might attribute to their extents of protection on necroptosis signaling.

Cell Death and Differentiation (2017) 24, 1459-1469; doi:10.1038/cdd.2017.78; published online 2 June 2017

The receptor-interacting protein kinase 1 (RIP1) functions as a key regulator for NF- $k \mathrm{~B}$ activation, apoptosis and necroptosis induced by tumor necrosis factor (TNF- $a) .{ }^{1-4}$ Upon TNF- $a$ activation, ligation of TNFR1 recruits pro-survival components including RIP1, TRADD, TRAF2 and NEMO to activate NF- $k$ B signaling pathway, even though RIP1 requirement for NF- $k B$ activation is controversial. ${ }^{5-9}$ When NF- $k B$ activation is impaired, RIP1 recruits TRADD to associate with FADD, which then activates Caspases to execute apoptosis. ${ }^{10-16}$ When apoptosis is inhibited by blocking Caspase-8 or FADD, RIP1 triggers necroptosis through assembling the necrosome complex with RIP3 and MLKL. ${ }^{17-19}$

RIP1 is a serine/threonine kinase with an N-terminal kinase domain, a RIP homotypic interaction motif (RHIM) and a C-terminal death domain (DD). Kinase activity of RIP1 is essential for necroptosis signaling, which can be blocked by RIP1 kinase inhibitor necrostatin-1 (Nec-1). ${ }^{20}$ RIP1 kinase activity is also required for apoptotic cell death under certain conditions. For an instance, apoptosis induced by TNF- $a$ and Smac mimetics can be inhibited by $\mathrm{Nec}-1$, suggesting that RIP1 kinase activity is indispensable for apoptosis under this condition. ${ }^{21-23}$ In addition to the roles of RIP1 kinase in necroptosis and apoptosis signaling pathways, a recent study revealed a novel role for RIP1 kinase activity in mediating
TNF- $a$ production under certain conditions, ${ }^{24}$ indicating that RIP1 kinase activity may serve more functions. Structural studies reveal that the kinase domain of RIP1 contains a canonical kinase fold with the catalytic triad residues Lys45/ Glu63/Asp156, a P-loop comprising residues 24-31 and a catalytic loop comprising residues $136-143 .{ }^{25}$ In agreement with the structural studies, cells expressing mutation $\mathrm{K} 45 \mathrm{~A}$ in the catalytic triad residues or D138N in the catalytic loop showed reduction in kinase activity and resistance to necroptotic death in vitro and in vivo. ${ }^{26,27}$ Whether residues 24-31 in the P-loop structure are essential for RIP1 kinase activity remains unknown.

Although ablation of Rip1 in mice results in perinatal death, ${ }^{28}$ mice expressing a kinase-dead mutant (K45A or $\mathrm{D} 138 \mathrm{~N}$ ) survive to adulthood, suggesting that kinase activity of RIP1 is dispensable for development. ${ }^{26,27,29,30}$ Recent genetic studies showed that deletion of Rip1, Rip3 or Mlkl rescues embryonic lethality of Fadd-or Caspase-8-deficient mice. ${ }^{31-35}$ Mice with concurrent ablations of Rip1 and Fadd or Caspase-8 have the same perinatal death as $\mathrm{Rip}^{-1-}$ mice, while

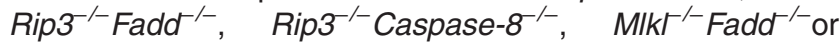
$\mathrm{MlkI}^{-1}$ Caspase- $8^{-1-}$ mice can survive to adulthood, indicating that FADD/Caspase-8 is critical for embryogenesis via inhibiting RIP1-/RIP3-/MLKL-dependent

\footnotetext{
${ }^{1}$ Key Laboratory of Nutrition and Metabolism, Institute for Nutritional Sciences, Shanghai Institutes for Biological Sciences, Chinese Academy of Sciences, University of Chinese Academy of Sciences, Shanghai 200031, China; '²epartment of Plastic and Reconstructive Surgery, Shanghai Ninth People's Hospital, Shanghai Jiao Tong University, Shanghai 200011, China; ${ }^{3}$ Department of Biochemistry, Hubei University of Medicine, Shiyan 442000, China; ${ }^{4}$ Department of Anesthesiology, Changhai Hospital, Second Military Medical University, Shanghai 200433, China; ${ }^{5}$ Key Laboratory of Food Safety Research, Institute for Nutritional Sciences, Shanghai Institutes for Biological Sciences, Chinese Academy of Sciences, University of Chinese Academy of Sciences, Shanghai 200031, China and ${ }^{6}$ Shanghai Key Laboratory of Regulatory Biology, Institute of Biomedical Sciences and School of Life Sciences, East China Normal University (ECNU), Shanghai, China

${ }^{*}$ Corresponding author: H Zhang, Key Laboratory of Nutrition and Metabolism, Institute for Nutritional Sciences, Shanghai Institutes for Biological Sciences, Chinese Academy of Sciences, University of Chinese Academy of Sciences, 320 Yueyang Road, Shanghai 200031, China. Tel/Fax: +86 21 54920988; E-mail: hbzhang @ sibs.ac.cn ${ }^{7}$ These authors contributed equally to this work.

Received 30.7.16; revised 06.4.17; accepted 26.4.17; Edited by J. Silke; published online 02.6.17
} 
necroptosis. ${ }^{28,29,31,32,36}$ Although it is required for necroptosis signaling, a role of RIP1 kinase activity of RIP1 on the development of Fadd-deficient mice has not been demonstrated. In this study, we generated two different RIP1 kinase inactive mutants and evaluated their impacts on embryogenesis of Fadddeficient mice.

\section{Results}

RIP1 kinase-dead (RIP1 ${ }^{\mathrm{K} 45 \mathrm{~A}}$ ) mutant has little effect on embryonic lethality of Fadd-deficient mice. To study the roles of RIP1 kinase activity in necroptosis of Fadd-deficient mice, we generated RIP1 kinase-dead knockin mice with point mutation in the catalytic lysine K45 (Rip $1^{\text {K45A }}$ ) (Supplementary Figure S1a). Consistent with previous reports, ${ }^{15,16}$ RIP1

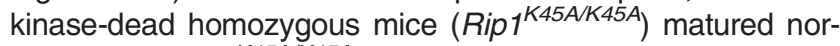
mally and Rip $1^{K 45 A / K 45 A}$ cells resisted necroptotic stimuli, indicating that $R i p 1^{K 45 A / K 45 A}$ cells might bypass the necroptosis signaling pathway like Rip1 knockout cells (data not shown). Although ablation of Rip1 can prevent embryonic lethality of $\mathrm{Fadd}^{-1}$ mice, ${ }^{33}$ the mechanisms remain unclear. To investigate the potential in vivo functional interaction between RIP1 kinase activity and FADD, we crossed the Fadd null allele

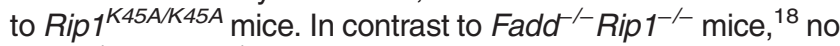
Fadd $^{-1}$ Rip $^{K 45 A / K 45 A}$ mice were identified among 146 perinatal pups from $\mathrm{Fadd}^{+/-} \mathrm{Rip}^{+/ K 45 A}$ intercrosses, indicating that

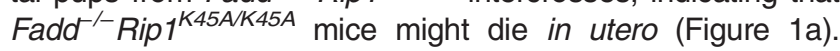
Subsequently, we examined embryos at various times during


around embryonic day 11.5 just like Fadd $^{-/}$embryos (Figures $1 \mathrm{~b}$ and $\mathrm{c}$ ). Thus, although kinase-dead RIP1 ${ }^{\mathrm{K} 45 \mathrm{~A}}$ blocks necroptotic signaling in certain context, a putative RIP1 kinase activity-independent signaling pathway mediates the embryonic lethality of Fadd-deficient mice.

RIP1 ${ }^{\Delta}$, a novel RIP1 kinase-dead mutation, abolishes TNF-induced necroptosis in vitro while is dispensable for cerulein-induced pancreatitis. The X-ray crystal structure of the RIP1 kinase domain shows that the kinase fold of RIP1 contains the catalytic triad residues Lys45/Glu63/Asp156, the key residues in the P-loop (residues 24-31) and the catalytic loop (residues 136-143). ${ }^{25}$ In line with the structure of RIP1 kinase domain, previous studies have shown that RIP1 ${ }^{\mathrm{K} 45 \mathrm{~A}}$ and RIP1 ${ }^{\mathrm{D} 138 \mathrm{~N}}$ were kinase-dead mutants, which abolished necroptosis signaling in vitro and in vivo. ${ }^{26,27}$ However, whether disrupting the RIP1 P-loop could also affect its kinase activity remains undefined. To address this question, we generated a RIP1 kinase domain mutant, $\mathrm{RIP}^{{ }^{\Delta}}$, in which only two amino acids $\mathrm{G}_{26} \mathrm{~F}_{27}$ in the P-loop of RIP1 were deleted (Supplementary Figure S1b). These two amino acids are highly conserved in many species, including Homo sapiens, Mus musculus, Danio rerio as well as Xenopus laevis (Supplementary Figure S1b). Although RIP1 kinase substrates have not been formally identified, previous studies have verified that RIP1 can be autophosphorylated. ${ }^{20,26,27}$ To test whether RIP1 ${ }^{\Delta}$ has lost the kinase activity, we examined RIP1 autophosphorylation in mouse dermal fibroblasts (MDFs) treated by TNF plus Smac mimetic and zVAD. As shown in Figure 2a, autophosphorylations in $\mathrm{RIP}^{\Delta}$ and a

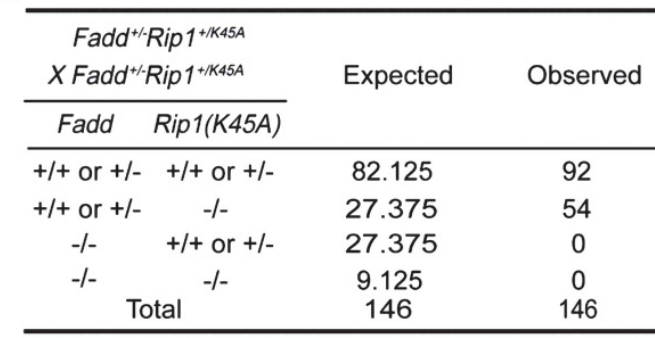

b

\begin{tabular}{|c|c|c|c|c|}
\hline \multicolumn{3}{|c|}{$\begin{array}{l}\text { Fadd }^{+/} \text {Rip } 1^{\text {K45A/K45A }} \\
\times \text { Fadd }^{+/} \text {Rip }^{\text {K45AK45A }}\end{array}$} & \multirow[t]{2}{*}{ Expected } & \multirow[t]{2}{*}{ Observed } \\
\hline & Fadd & $\operatorname{Rip1}(K 45 A)$ & & \\
\hline \multirow{2}{*}{ E11.5 } & $+/+$ or $+/-$ & $-1-$ & 31.5 & 28 \\
\hline & $-1-$ & $-1-$ & 10.5 & 14 \\
\hline \multirow{2}{*}{ E12.5 } & $+1+$ or $+1-$ & $-1-$ & 33.75 & 40 \\
\hline & $-1-$ & $-1-$ & 11.25 & 5 \\
\hline
\end{tabular}

c

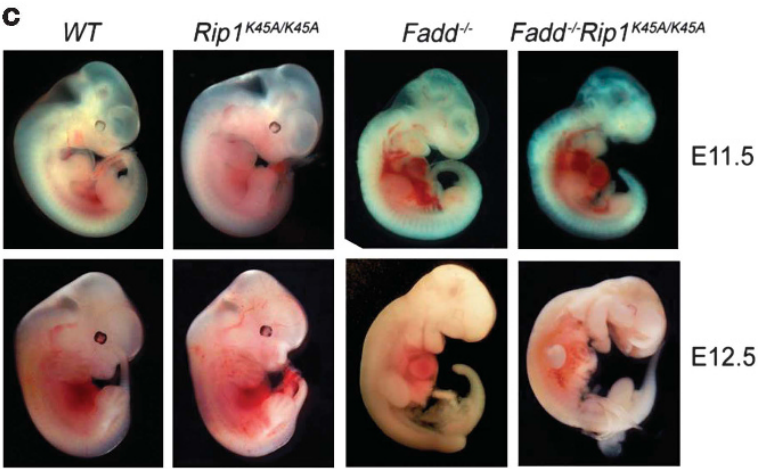

Figure 1 RIP1 kinase-dead (RIP1 ${ }^{\mathrm{K} 45 \mathrm{~A}}$ ) has little effect on embryonic lethality of Fadd-deficient mice. (a) Expected and observed numbers of genotypes in offspring at weaning from intercrosses of Fadd ${ }^{+/-}$Rip $^{+/ / K 45 A}$ mice. (b) Expected and observed numbers of E11.5 and E12.5 embryos. (c) Representative photographs of E11.5 and E12.5 embryos from indicated genotypes. Fadd ${ }^{-/}$control mice are $\mathrm{Fadd}^{+/+}$, Fadd ${ }^{-/-}$Rip $1^{\text {K45AK45A }}$ control mice are Rip $1^{\text {K45AKK45A }}$

RIP K45A were significantly attenuated comparing to wild-type (WT) RIP1. Furthermore, among various Flag-tagged RIP1 proteins (Flag-RIP1, Flag-RIP1 ${ }^{\mathrm{K} 45 \mathrm{~A}}$ and Flag-RIP1 ${ }^{\Delta}$ ) expressed in 293T cells, only Flag-RIP1 could be autophosphorylated (Figure $2 b$ ). Similar to Rip $1^{K 45 A / K 45 A}$ mice, Rip $1^{\Delta / \Delta}$ mice were viable and born at the expected Mendelian ratios (data not shown), and displayed normal littermate sizes from heterozygous breeding paradigms (Supplementary Figure S1c). Compared to WT mice, multiple tissues from both Rip $1^{K 45 A / K 45 A}$ mice and Rip $1^{\Delta / \Delta}$ mice showed mild decreased levels of RIP1 proteins (Supplementary Figure S1d). Furthermore, we observed that myeloid cells, $\mathrm{T}$ cells and $\mathrm{B}$ cells from Rip ${ }^{\Delta / \Delta}$ mice were present in normal proportions as WT mice (Supplementary Figures S2a and b). Given the fact that RIP1 interacts with RIP3 through its RHIM domain, ${ }^{37-39}$ we tested whether $\mathrm{RIP}^{\Delta}{ }^{\Delta}$ had impaired interaction with RIP3 when RIP1 ${ }^{\Delta}$ and RIP3 were overexpressed in 293T cells. Co-immunoprecipitation of $\mathrm{RIP}^{\Delta}$ and RIP3 (Supplementary Figure S3) indicates that the physical 
a



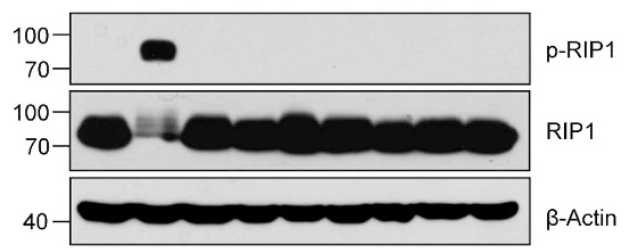

b



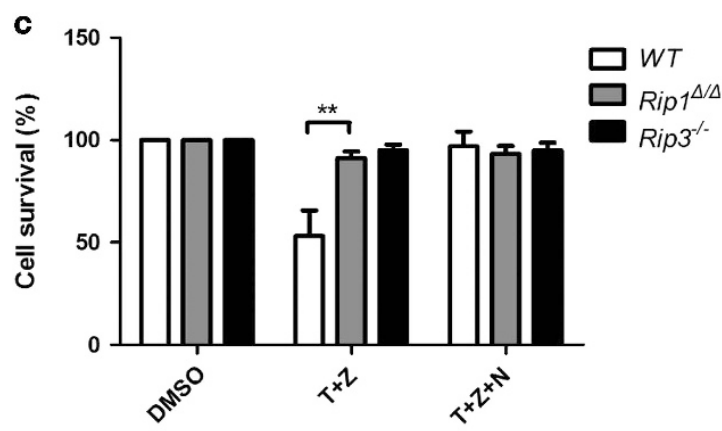
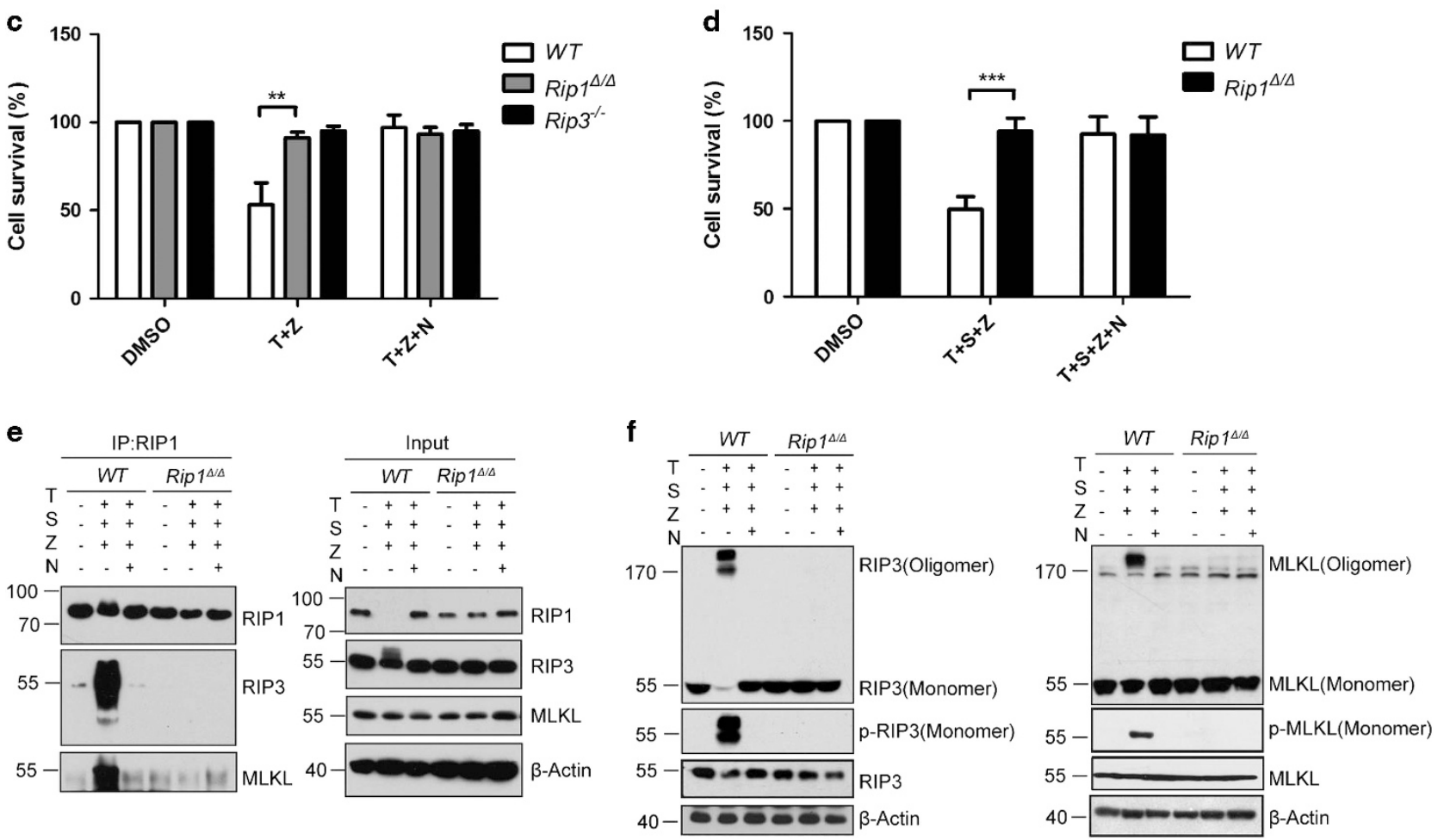

Figure $2 \mathrm{RIP1}^{\Delta}$, a novel RIP1 kinase-dead mutation, abolishes TNF-induced necroptosis in vitro. (a) MDFs from Rip ${ }^{K 45 A / K 45 A}$, Rip ${ }^{1 / \Delta}$ and control wild-type mice were treated as indicated for $3 \mathrm{~h}$ with DMSO, mouse TNF- $\alpha(100 \mathrm{ng} / \mathrm{ml})+$ Smac mimetic $(1 \mu \mathrm{M})+\mathrm{ZVAD}(20 \mu \mathrm{M})$ or mouse TNF- $\alpha+S m a c$ mimetic $+\mathrm{ZVAD}+\mathrm{Necrostatin}-1(30 \mu \mathrm{M})$, respectively. Cell lysates were collected and subjected to western blot analysis of RIP1, $\mathrm{p}$-RIP1 and $\beta$-actin levels. (b) Autophosphorylation of RIP1 requires its kinase activity. Over expression constructs of Flag, Flag-tagged RIP1, RIP1 ${ }^{\mathrm{K} 45 \mathrm{~A}}$ and RIP1 ${ }^{\Delta}$ were transfected into $293 \mathrm{~T}$ cells. Cell lysates were subjected to western blot analysis using the anti-pRIP1 (S166) antibody. (c) Wild-type, Rip $1^{\Delta / \Delta}$ and Rip3 ${ }^{-1-}$ BMDMs were treated with DMSO, TZ and TZN (T:20 ng/ml, Z:20 $\left.\mu \mathrm{M}, \mathrm{N}: 30 \mu \mathrm{M}\right)$ for $12 \mathrm{~h}$. Cell viability was determined by measuring intracellular ATP levels with a Cell Titer-Glo Luminescent Cell Viability Assay kit. Data are represented as the mean \pm S.E.M. of three independent experiments. ${ }^{* *} P<0.0005$ by Student's $t$-test. (d) Rip $1^{1 / \Delta}$ and Wild-type control MDFs were treated with DMSO, TSZ and TSZN for $12 \mathrm{~h}$. Cell viability was determined by measuring intracellular ATP levels with a Cell Titer-Glo Luminescent Cell Viability Assay kit. Data are represented as the mean \pm S.E.M. of three independent experiments. ${ }^{* \star \star} P<0.0001$ by Student's $t$-test. (e) Immunoprecipitates of RIP1 from WT and Rip $1^{\Delta / 4}$ MDFs treated with DMSO, TSZ and TSZN for $2 \mathrm{~h}$ were subjected to western blot analysis to detect the associations with RIP3 and MLKL. (f) MDF cells were treated with DMSO, TSZ and TSZN, respectively, for $3 \mathrm{~h}$. Cell lysates were collected and subjected to western blot analysis of RIP3, $\mathrm{p}$-RIP3, MLKL, p-MLKL and $\beta$-actin levels. D, DMSO; N, necrostatin-1; S, smac mimetic; T, mouse TNF- $\alpha$; Z, zVAD

domain of interaction between RIP1 and RIP3 was intact in $\mathrm{RIP} 1^{\Delta}$. To test if $\mathrm{RIP}^{\Delta}{ }^{\Delta}$ could disrupt inflammatory signaling pathways normally mediated by RIP1, WT and Rip $1^{\Delta / \Delta}$ BMDMs were treated with LPS, and activation statuses of $\mathrm{NF}-\mathrm{KB}$ and MAPK signaling pathways were investigated. As shown in Supplementary Figure $\mathrm{S} 4, \mathrm{RIP}^{\Delta}{ }^{\Delta}$ appeared to have no effect on LPS-induced activation of $\mathrm{NF}-\mathrm{KB}$ and MAPK pathways in BMDMs, as assessed by the phosphorylation of P65, IKB, JNK, ERK1/2 and P38 in BMDMs (Supplementary Figure S4). To further test whether $R I P 1^{\Delta}$ has effects on apoptosis signaling, we stimulated
MDFs from Rip $1^{K 45 A / K 45 A}$, Rip $1^{-/-}$, Rip $1^{\Delta / \Delta}$ as well as WT control mice with TNF, and found that Rip $1^{\Delta / \Delta}$ and Rip ${ }^{\text {K45A/K45A }}$ MDFs were resistant to TNF plus Smac but not TNF plus CHX-induced apoptosis (Supplementary Figures S5a, b and c). We next investigated whether RIP1 ${ }^{\Delta}$ can block necroptotic cell death induced by TNF. Rip $1^{\Delta / \Delta}$ MDFs, mouse embryonic fibroblasts (MEFs) and BMDMs were treated with TNF plus $\mathrm{CHX}$ or Smac mimetic, in the presence of the ZVAD and/or Nec-1. Similar to Rip $1^{-/}$and Rip $3^{-1}$ cells, Rip $1^{\Delta / \Delta}$ cells showed resistant to necroptosis compared to WT control cells (Figures 2c and d; 
a


b
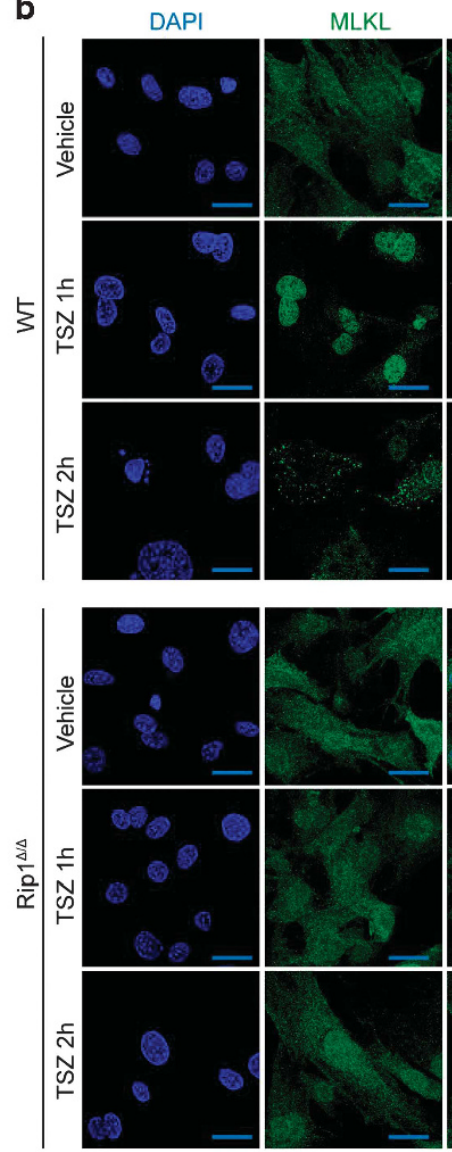

Merge


Figure $3 \mathrm{RIP1}^{\Delta}$ blocks oligomerization of RIP3/MLKL and nuclear translocation of MLKL in MDFs. (a) Immunostaining of RIP1 (green) and RIP3 (red) on wild-type and Rip $1^{\Delta / \Delta}$ MDFs stimulated with DMSO or TSZ. DAPI (blue) was used for nuclear staining. Scale bar, $5 \mu$ m. (b) Immunostaining of MLKL (green) on wild-type and Rip $1^{\Delta / \Delta}$ MDFs stimulated with DMSO or TSZ. DAPI (blue) was used for nuclear staining. Scale bar, $5 \mu \mathrm{m}$

Supplementary Figures S6a and c). Necroptotic cell death is sequentially mediated by necrosome containing RIP1, RIP3 and MLKL, and subsequent MLKL oligomer formation triggered by RIP3 phosphorylation. ${ }^{40-43}$ Thus, we next investigated whether these hallmarks for necroptosis induction were blocked in $\operatorname{Rip}^{\Delta / \Delta}$ cells. Co-immunoprecipitation assay showed that RIP1 ${ }^{\Delta}$, RIP3 and MLKL failed to form necrosome (Figure 2e). Furthermore, oligomerization and phosphorylation of RIP3 as well as MLKL were detectable in

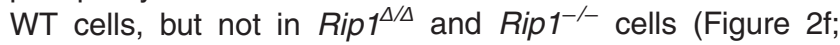
Supplementary Figures S6b and d). In agreement with this observation, immunofluorescence analyses showed that oligomerization of RIP1/RIP3/MLKL following TNF/Smac/ ZVAD treatment was significantly reduced in $R i p 1^{\Delta / \Delta}$ cells compared to WT cells (Figures $3 a$ and b), indicating that $\mathrm{RIP}^{\Delta}$ had impaired necroptotic signaling in vitro. Previous reports have shown that induction of necroptosis in HT29 cells, L929 cells and MEFs can trigger nuclear translocation of MLKL. ${ }^{44}$ Concomitantly, we also observed that MLKL translocated to nuclei at the early stage $(1 \mathrm{~h})$ of TSZ-induced necroptosis. However, as shown in the bottom section of Figure $3 b$, there was no nuclear translocation of MLKL in TSZ-treated Rip $1^{\Delta / \Delta}$ MDFs. These findings suggested that $\mathrm{RIP}^{\Delta}{ }^{\Delta}$ could inhibit the necropototic signaling through blocking phosphorylation, oligomerization or nuclear translocation of MLKL in vitro.

Previous works have shown that Rip3 or Mlk/knockout mice were protected from cerulein-induced acute pancreatitis in vivo. ${ }^{18,45}$ We investigated whether $\mathrm{RIP}^{\Delta}{ }^{\Delta}$ could defend against this pathology. However, Rip $1^{\Delta / \Delta}$ mice showed severe tissue damage and high levels of serum amylase activity as WT littermate controls, while these effects were largely prevented in Rip3 knockout mice (Figures $4 a$ and b). These results suggested that there may be additional mechanisms rather than kinase activity of RIP1 in mediating necroptosis signaling in cerulein-induced acute pancreatitis mouse model.

\section{Homozygous $\operatorname{Rip}^{\Delta / \Delta}$ can rescue embryonic lethality of} Fadd $^{-/}$mice at E10.5, and Fadd ${ }^{/-}$Rip1 $^{\Delta / \Delta}$ mice eventually die at E16.5. As Fadd ${ }^{-1}$ Rip $1^{K 45 A / K 45 A}$ mice did not display any improved survival versus animals lacking Fadd alone, suggesting that the embryonic lethality caused by loss of Fadd was not due to RIP1 ${ }^{\mathrm{K} 45 \mathrm{~A}}$-abolished signaling. We asked whether RIP1 ${ }^{\Delta}$, the novel kinase-dead mutant, had distinct functions on embryonic development of $\mathrm{Fadd}^{-/}$mice. After crossing $\mathrm{Rip}^{\Delta}{ }^{-}$-mutant allele into $\mathrm{Fadd}^{+/-}$mice, we observed that no Fadd ${ }^{-/}$Rip $1^{\Delta / \Delta}$ mice were identified among 96 perinatal pups from $\mathrm{Fadd}^{+/-} \mathrm{Rip}^{\Delta / \Delta}$ intercrosses, 
indicating that $\mathrm{Fadd}^{-/} \mathrm{Rip}^{\Delta / \Delta}$ mice might die in utero (Figure 5a). Subsequently, we examined embryos at various times during gestation and found that $\mathrm{Fadd}^{-1} \mathrm{Rip}^{\Delta / \Delta}$ embryos died between embryonic days 14.5 and 16.5 (Figures $5 \mathrm{a}$ and b). Although Fadd $^{-/}$Rip $^{\Delta / \Delta}$ mice did not survive to birth, we observed that these animals progressed a
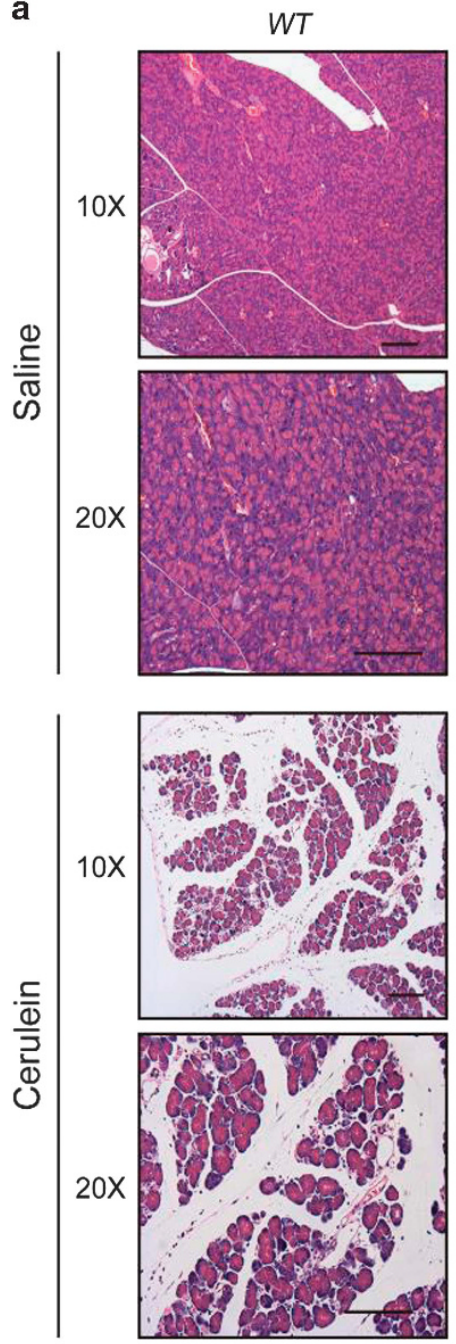

b

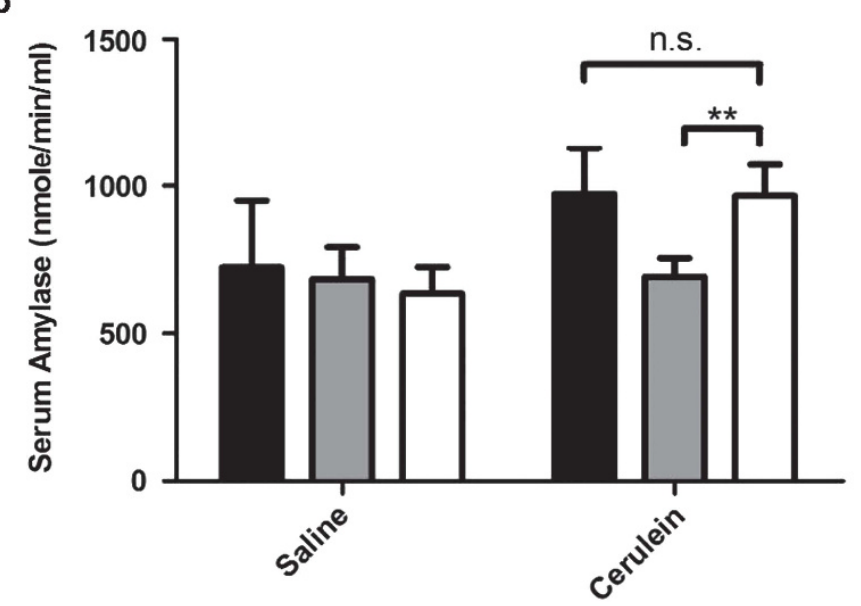

Rip3\%
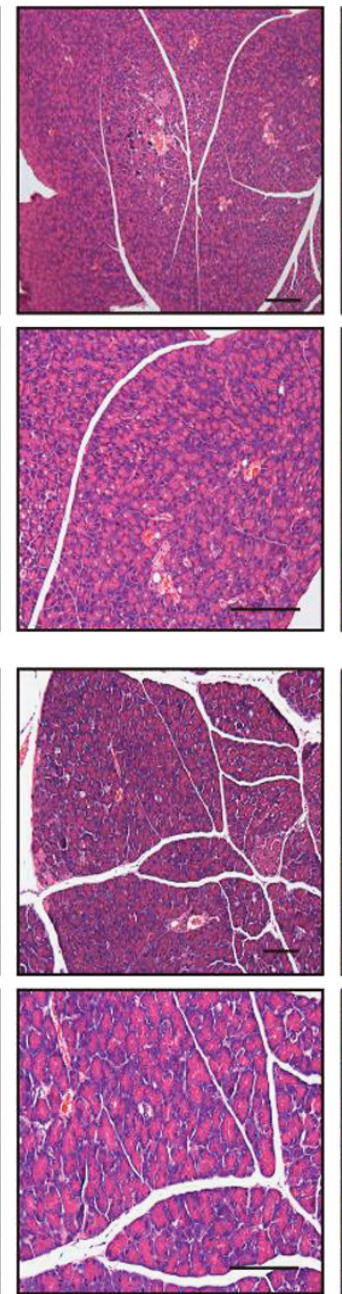

$\operatorname{Rip}^{\Delta / \Delta}$
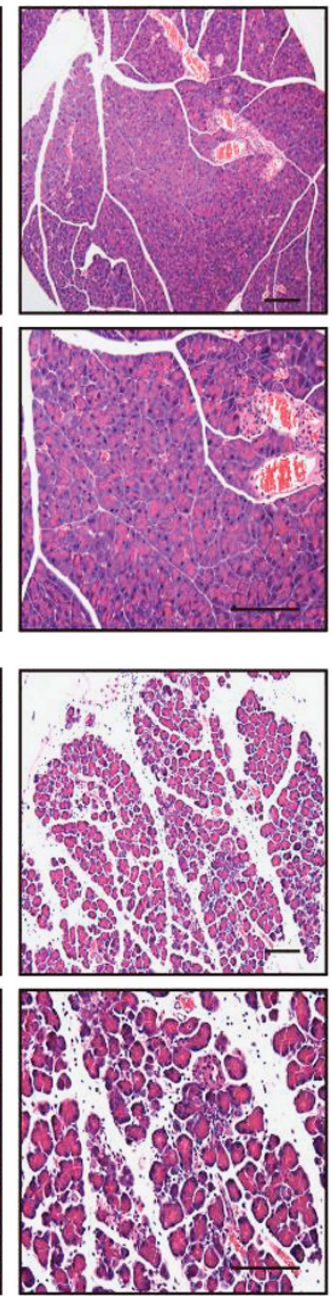

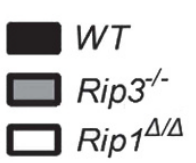

Figure $4 \mathrm{RIP}^{\Delta}$ has no effect on cerulein-induced pancreatitis. (a) Hematoxylin and Eosin staining on pancreatic tissue from mice with indicated genotypes. Scale bar, $100 \mu \mathrm{m}$. (b) Serum amylase activity was measured using Amylase Assay Kit. The results shown here are representative of seven animals. ${ }^{\star *} P<0.0005$ by Student's $t$-test. Error bars represent mean \pm S.E.M. 
well till E14.5. From E14.5, the fetal liver of Fadd $^{-1}$ Rip $1^{\Delta / \Delta}$ embryo started to become darker, and its anatomy exhibited massive hemorrhaging and degeneration. H\&E staining showed excessive cell death in fetal liver of Fadd $^{-1}$ Rip $1^{\Delta / \Delta}$ embryo (Figure 5c). Lethality in Fadd-deficient embryos is driven by necroptosis, as RIP3/MLKL defect completely a

\begin{tabular}{|c|c|c|}
\hline $\begin{array}{l}\text { Fadd }^{+/-R i p} 1^{\Delta / \Delta} \\
X \text { Fadd }^{+-} \text {Rip } 1^{\Delta / \Delta}\end{array}$ & Expected & $\begin{array}{l}\text { Observed } \\
\text { (Newborn) }\end{array}$ \\
\hline Fadd $^{+/+} R_{i p} 1^{\Delta / \Delta}$ & 24 & 35 \\
\hline Fadd ${ }^{+/-R i p} 1^{\Delta / \Delta}$ & 48 & 61 \\
\hline Fadd ${ }^{-} \operatorname{Rip}^{1 \Delta / \Delta}$ & 24 & 0 \\
\hline Total & 96 & 96 \\
\hline $\begin{array}{r}\text { Fadd }^{++} \text {Rip } 1^{\Delta / \Delta} \\
X \text { Fadd }\end{array}$ & Expected & $\begin{array}{l}\text { Observed embryos } \\
\text { (E13.5-E16.5) }\end{array}$ \\
\hline Fadd $^{+/+} \operatorname{Rip}^{\Delta / \Delta}$ & 20.5 & 15 \\
\hline Fadd $^{+/}$Rip $1^{\Delta / \Delta}$ & 41 & 46 \\
\hline $\mathrm{Fadd}^{\top /} \operatorname{Rip} 1^{\Delta \Delta}$ & 20.5 & 21 \\
\hline Total & 82 & 82 \\
\hline
\end{tabular}

b
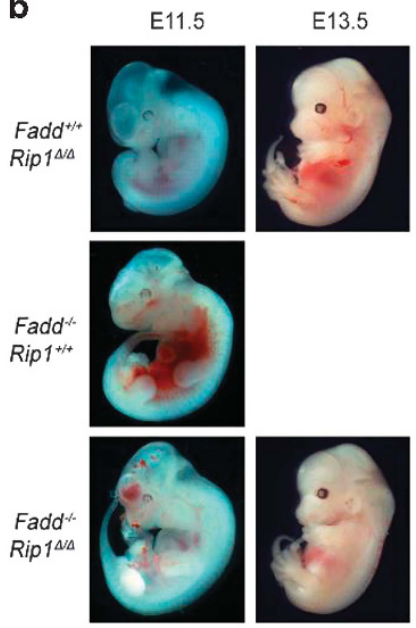
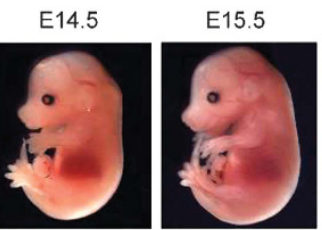

E16.5
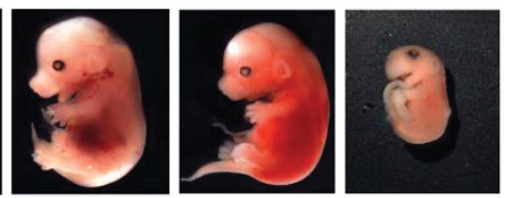

C
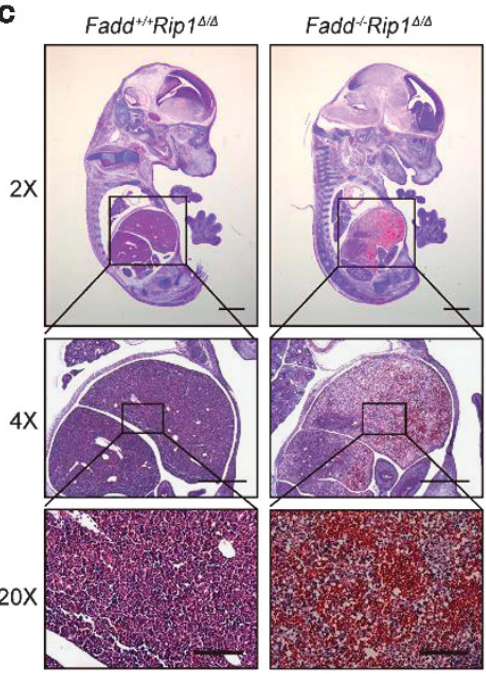

d
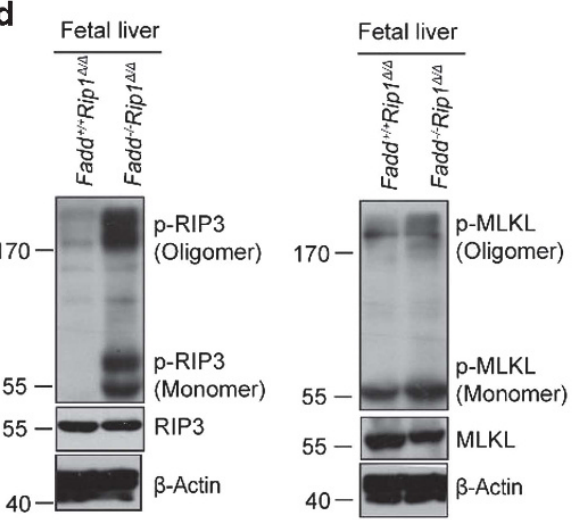

e

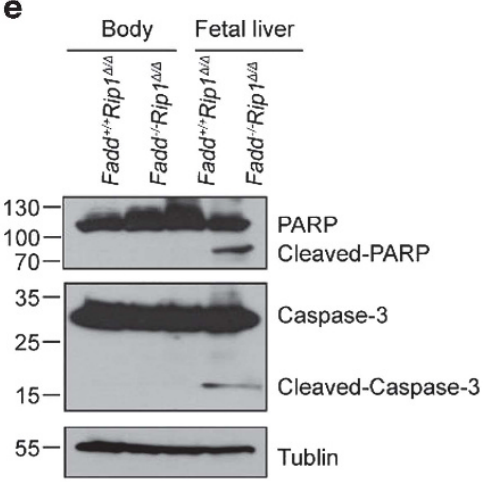

$\mathbf{f}$

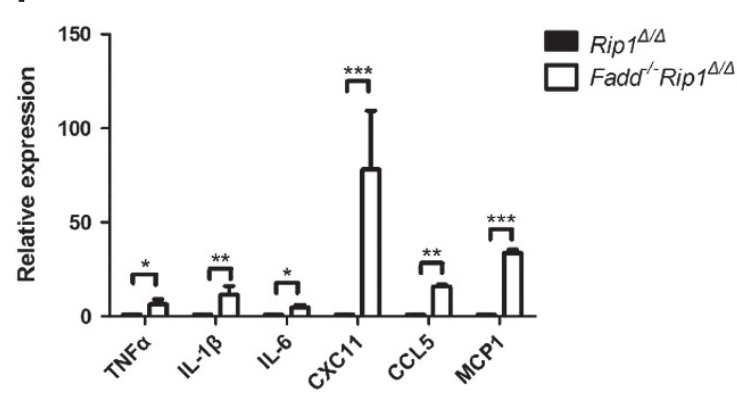

g
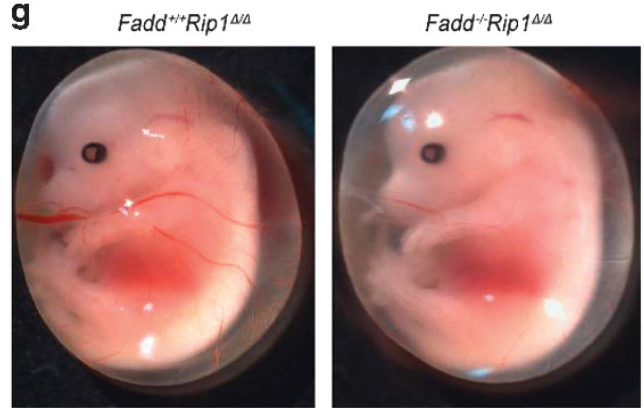

Figure $5 \mathrm{RIP} 1^{\Delta}$ rescues the lethality of $\mathrm{Fadd}^{-\alpha}$ mice at E10.5, and Fadd ${ }^{-1-} \mathrm{Rip}^{\mathrm{\Delta}}{ }^{/ \Delta}$ mice eventually died at E16.5 due to massive cell death and inflammation. (a) Predicted and observed numbers of genotypes in offspring as well as embryos at weaning from Fadd ${ }^{+/}$Rip $1^{\Delta / \Delta}$ intercrosses. (b) Representative photographs of Rip $1^{\Delta / \Delta}$, Fadd ${ }^{-/}$and Fadd ${ }^{-1}$ Rip $1^{\Delta / \Delta}$ embryos at various times during gestation. Control mice are Rip $1^{\Delta / \Delta}$. (c) H\&E staining on E14.5 Fadd ${ }^{\prime-}$ Rip $1^{\Delta / \Delta}$ and littermate Rip $1^{\Delta / \Delta}$ control embryos sections. Scale bar, $2 \times, 4 \times: 500 \mu \mathrm{m} ; 20 \times: 100 \mu \mathrm{m}$. (d) Rip $1^{\Delta / \Delta}$ and littermate Fadd ${ }^{-1}$ Rip $1^{1 / \Delta}$ fetal livers were isolated and lysates were subjected to western blot analysis of p-RIP3, $\mathrm{p}$-MLKL, RIP3, MLKL and $\beta$-actin levels. Control mice are Rip $1^{\Delta / \Delta}$. (e) $\operatorname{Rip}^{1 / \Delta}$ and littermate Fadd ${ }^{-/}$Rip $^{\Delta / /}$ fetal liver or body (tissues excluding fetal liver) were isolated and

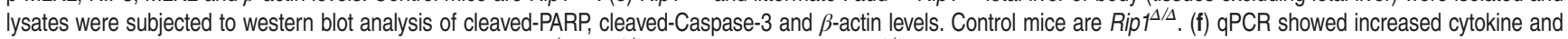
chemokine mRNA expression in E14.5 fetal livers from Fadd ${ }^{-1-}$ Rip $^{1 / \Delta}$ and littermate control Rip ${ }^{1 / \Delta}$ embryos. Data representative of three independent experiments with three mice of each genotype analyzed together. ${ }^{*} P<0.001,{ }^{* *} P<0.0005,{ }^{* \star} P<0.0001$ by Student's $t$-test. Error bars represent mean \pm S.E.M. (g) Representative photographs of $\operatorname{Rip}^{\Delta / \Delta}$ and Fadd ${ }^{-1-}$ Rip $^{\Delta / \Delta}$ yolk sac at E14.5. Control mice are Rip $1^{\Delta / \Delta}$ 
a

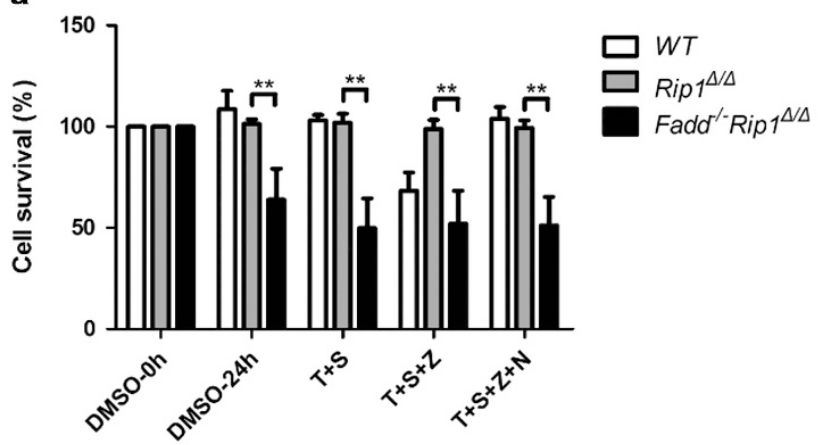

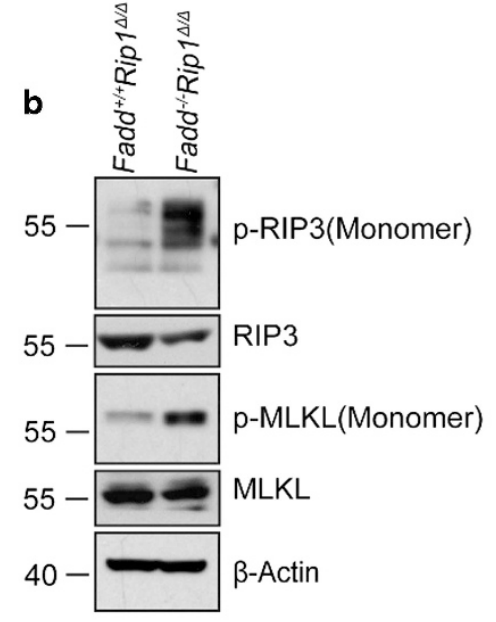
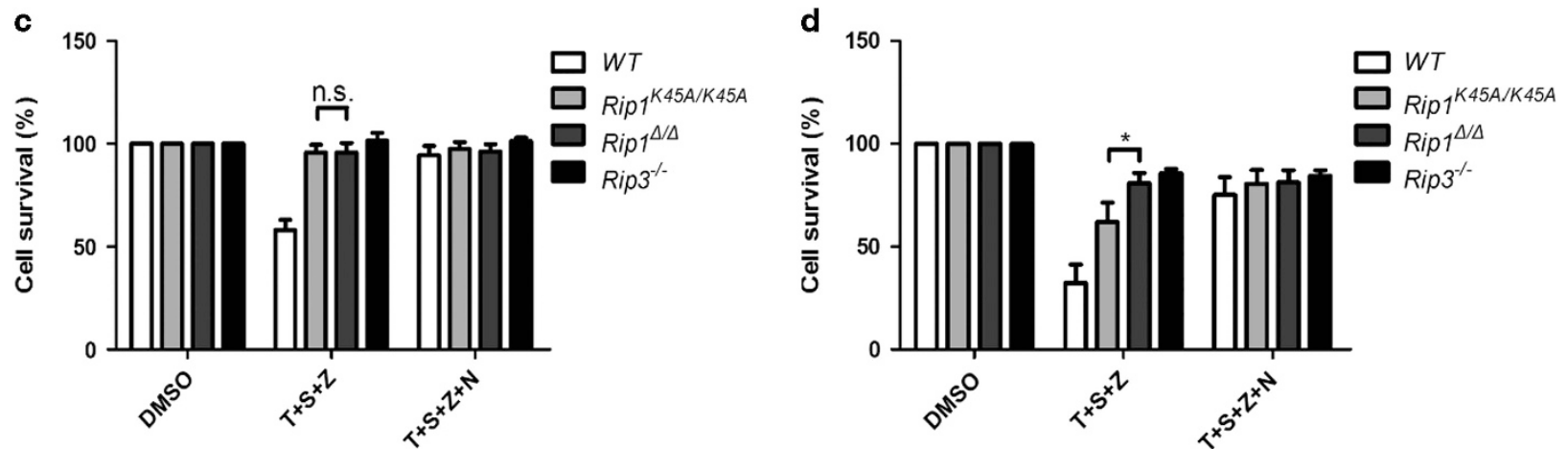

$\mathbf{e}$
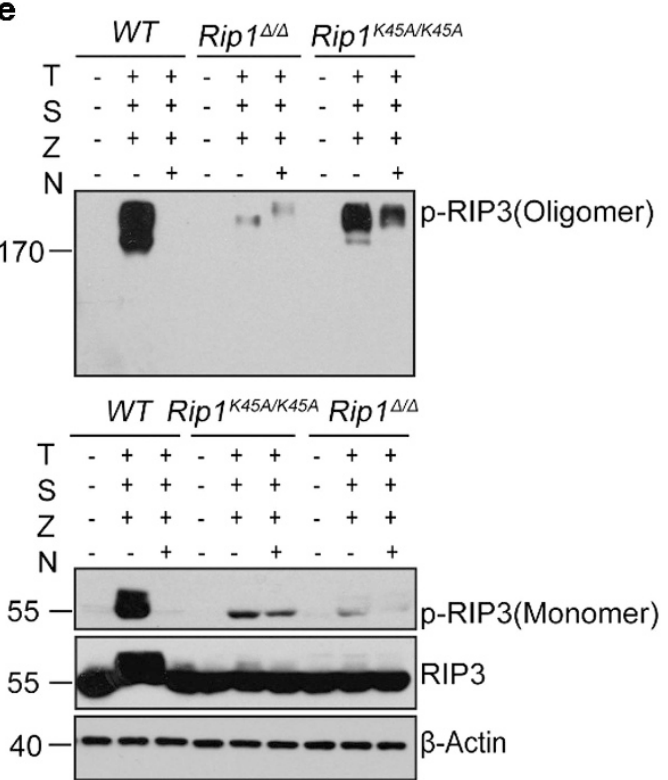
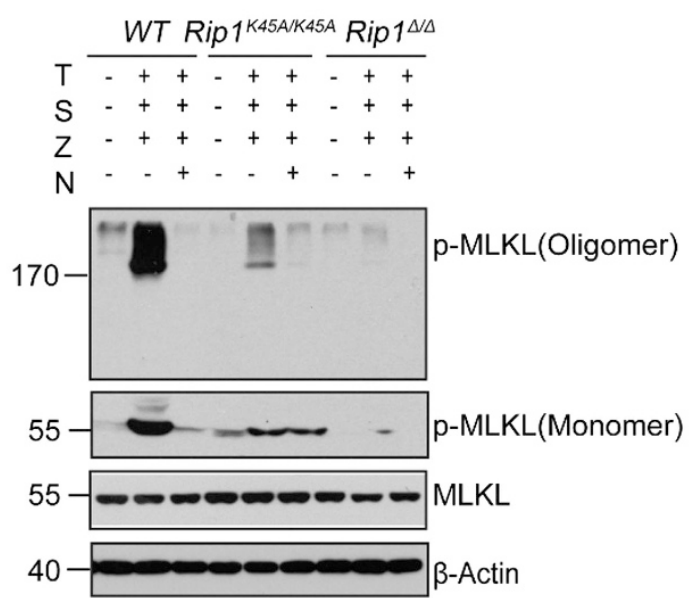

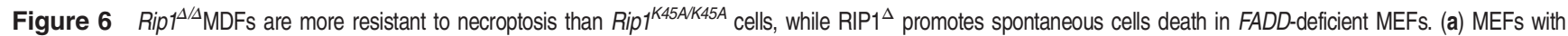
indicated genotypes were treated with DMSO, TNF $(30 \mathrm{ng} / \mathrm{ml})+S$ mac mimetic $(10 \mathrm{nM}), \mathrm{TNF}+\mathrm{Smac}$ mimetic $+\mathrm{ZVAD}(20 \mu \mathrm{M}), \mathrm{TNF}+\mathrm{Smac}$ mimetic $+\mathrm{ZVAD}+\mathrm{Nec}-1$ (30 $\mu \mathrm{M})$, respectively, for $24 \mathrm{~h}$. Cell viability was determined by measuring intracellular ATP levels with a Cell Titer-Glo Luminescent Cell Viability Assay kit. ${ }^{* *} P<0.0005$ by Student's $t$-test. Data are represented as the mean \pm S.E.M. of three independent experiments. (b) Rip $1^{\Delta / \Delta}$ and Fadd ${ }^{-1}$ Rip $1^{\Delta / \Delta}$ MEFs were subjected to western blot analysis of p-RIP3, p-MLKL, RIP3, MLKL and $\beta$-actin levels. Control cells are Rip $1^{\Delta / \Delta}$. (c) MDFs with indicated genotypes were treated with DMSO, TSZ and TSZN, respectively, for $3 \mathrm{~h}$. Cell viability was determined by measuring intracellular ATP levels with a Cell Titer-Glo Luminescent Cell Viability Assay kit. Data are represented as the mean \pm S.E.M. of three independent experiments. (d) MDFs with indicated genotypes were treated with DMSO, TSZ and TSZN, respectively, for $24 \mathrm{~h}$. Cell viability was determined by measuring intracellular ATP levels with a Cell Titer-Glo Luminescent Cell Viability Assay kit. ${ }^{*} P<0.001$ by Student's $t$-test. Data are represented as the mean \pm S.E.M. of three independent experiments. (e) MDFs with indicated genotypes were treated with DMSO, TSZ and TSZN, respectively, for $8 \mathrm{~h}$. Cell lysates were collected and subjected to western blot analysis of RIP3,p-RIP3, MLKL, p-MLKL and $\beta$-actin levels 
rescues the lethality. ${ }^{31-35}$ Thus, we explored whether cells in Fadd $^{-\alpha}$ Rip $^{\Delta / \Delta}$ fetal liver committed necroptotic death in vivo. We performed immunoblot of necroptosis markers ( $p$-RIP3 and $\mathrm{p}-\mathrm{MLKL}$ ) in $\mathrm{Fadd}^{-1}$ Rip $^{\Delta / \Delta}$ fetal liver cells. Indeed, we detected $\mathrm{p}-\mathrm{RIP3}$ and $\mathrm{p}-\mathrm{MLKL}$ accompanied by cleaved Caspase-3 and cleaved PARP, but not in littermate control Rip $1^{\Delta / \Delta}$ embryos, suggesting that these cells mainly died from necroptosis and apoptosis likely caused by unablated necroptosis in vivo (Figures $5 \mathrm{~d}$ and e). Additionally, previous studies suggested that FADD could protect cells from RIP3dependent necroptosis and prevent upregulation of cytokine and chemokine expression in vivo. ${ }^{46}$ Therefore, we examined cytokine and chemokine expression in fetal livers of Fadd $^{-/}$Rip $^{\Delta / \Delta}$ and littermate control Rip $1^{\Delta / \Delta}$ mice. Notably, we observed that cytokine and chemokine expression at E14.5 had significantly increased in $\mathrm{Fadd}^{-}{ }^{-} \mathrm{Rip}^{\Delta / \Delta}$ fetal livers compared to that in $\operatorname{Rip} 1^{\Delta / \Delta}$ fetal livers (Figure 5f). These results indicated that massive cell death and unregulated cytokine and chemokine production resulted in the Fadd $^{-1}$ Rip $^{\Delta / \Delta}$ fetal liver degeneration. Given that endothelial cell necroptosis is prominent in Caspase-8- or Fadd-deficient embryos. ${ }^{47,48}$ We next checked the yolk sac vasculature in all genotyped mice. We found that the yolk sac vasculature was scarce and weak in Fadd ${ }^{-/}$Rip $^{\Delta / \Delta}$ embryos at E14.5-E15.5 (Figure $5 \mathrm{~g}$ ). To further investigate whether $\mathrm{Fadd}^{-1} \mathrm{Rip}^{\Delta / \Delta}$ mice could die from necroptosis, we isolated MEFs from Fadd $^{-1}$ Rip $^{\Delta / \Delta}$ embryos to investigate the potential mechanism. WT, Rip $1^{\Delta / \Delta}$ and Fadd ${ }^{-1}$ Rip $1^{\Delta / \Delta}$ MEFs were cultured for $24 \mathrm{~h}$ in media alone or in the presence of TNF/Smac with either zVAD or zVAD/Nec-1. Unexpectedly, Fadd $^{-1}$ Rip $^{\Delta / \Delta}$ MEFs underwent greater spontaneous cell death compared to WT or Rip $1^{\Delta / \Delta}$ cells in the absence of treatments (Figure 6a; Supplementary Figure S7a). As shown in Figure 6a, this spontaneous cell death in Fadd $^{-1}$ Rip ${ }^{\Delta / \Delta}$ MEFs cannot be rescued by treatment with Z-VAD or Nec-1, indicating that the mechanism triggered cell death in $\mathrm{Fadd}^{-}{ }^{-} \mathrm{Rip}^{\Delta / \Delta}$ MEFs is independent of Caspase or RIP1 kinase activity. We speculated that activation of RIP3/MLKL might be responsible for the cell death in Fadd $^{-/}$Rip $^{\Delta / \Delta}$ MEFs. Indeed, there were significant increases of phosphorylated RIP3 and MLKL proteins in Fadd ${ }^{-1}$ Rip $^{\Delta / \Delta}$ MEFs (Figure 6b). This result indicated that RIP3 and MLKL were more activated in $\mathrm{Fadd}^{/-} \mathrm{Rip}^{\Delta / \Delta}$ MEFs than in Rip $1^{\Delta / \Delta}$ MEFs. Together, RIP3/MLKL but not RIP1 kinase-dependent necroptosis of $\mathrm{Fadd}^{-/} \mathrm{Rip}^{\Delta / \Delta}$ cells, and unregulated cytokine and chemokine production in fetal livers of Fadd $^{-/}$Rip $1^{\Delta / \Delta}$ mice might be responsible for the lethality of Fadd $^{-/}$Rip $1^{\Delta / \Delta}$ embryos at E16.5.

Rip $^{\Delta / \Delta}$ cells are more resistant to necroptosis than Rip $^{K 45 A / K 45 A}$ cells. RIP $1^{\mathrm{K} 45 A}$ and RIP1 ${ }^{\Delta}$ contain different RIP1 mutations in various regions essential for RIP1 kinase activity. Genetic studies showed that $\mathrm{RIP}^{\Delta}{ }^{\Delta}$ could rescue the lethality of $\mathrm{Fadd}^{-1}$ mice to E16.5, while RIP1 ${ }^{\mathrm{K} 45 \mathrm{~A}}$ has little effect on the lethality of $\mathrm{Fadd}^{-/}$mice. To investigate mechanism underlining this phenotypic difference, we treated WT, Rip $1^{K 45 A / K 45 A}$ and Rip $1^{\Delta / \Delta}$ MDFs with TNF-a/Smac/zVAD for time course or with gradient concentration of TNF- $a$. We have observed that cell death was largely suppressed in both Rip $1^{K 45 A / K 45 A}$ and Rip $1^{\Delta / \Delta}$ MDFs when the cells were treated for $2-6 \mathrm{~h}$ or with low concentration of TNF-a (Figure 6c; Supplementary Figure S7b). However, when we prolonged treatment time for $8-24 \mathrm{~h}$ or used high concentration of

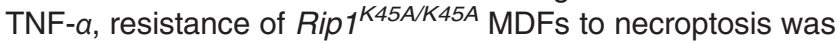
much weaker than that of Rip $1^{\Delta / \Delta}$ MDFs (Figure 6d; Supplementary Figure S7b). In necroptotic cells, RIP3 and MLKL could be phosphorylated and form oligomers upon treatment with TNF-a/Smac/zVAD. We performed western blot analysis on phosphorylation and oligomerization of RIP3 and $\mathrm{MLKL}$ following $8 \mathrm{~h}$ treatment. Consistent with the cell death results, phosphorylation and oligomerization of RIP3

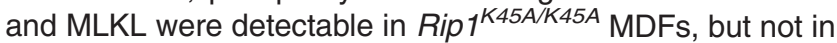
Rip $^{\Delta / \Delta}$ cells (Figure 6e). This may explain that RIP1 ${ }^{\mathrm{K} 45 \mathrm{~A}}$ and $\mathrm{RIP}^{\Delta}{ }^{\Delta}$ have distinct impacts on the lethality of $\mathrm{Fadd}^{-/}$mice, even though both of them show reduced kinase activity.

Collectively, these data suggested that RIP1 ${ }^{\Delta}$ blocks necroptosis signaling more thoroughly than RIP1 ${ }^{\mathrm{K} 45 \mathrm{~A}}$, while neither of them is sufficient to block necroptosis in the absence of FADD in vivo, which provides a putative mechanism for their distinct impacts on the lethality of Fadd-deficient mice.

\section{Discussion}

The catalytic triad residues Lys45/Glu63/Asp156, the key residues in the P-loop (residues 24-31) and the catalytic loop (residues 136-143), as functional subunits in the kinase domain of RIP1, are critical for RIP1 kinase activity. ${ }^{25}$ In this study, we have demonstrated that $\mathrm{RIP}^{\Delta}$ contains a novel RIP1 kinase inactive mutation in the P-loop of kinase domain (Figures 2a and b; Supplementary Figure S1b). Consistent with previous studies on other kinase-dead mutations of RIP1, ${ }^{15,16}$ our study showed that the P-loop of RIP1 played an essential role in mediating TNF-induced necroptosis, indicating that $\mathrm{RIP}^{\Delta}{ }^{\Delta}$ was nearly parallel to $\mathrm{RIP} 1^{\mathrm{K} 45 \mathrm{~A}}$ or RIP1 ${ }^{\mathrm{D} 138 \mathrm{~N}}$ roles in necroptosis (Figures 2c-f; Supplementary Figures S6c and d). Recent report showed that K45A mutation of RIP1 resulted in poor necroptosis in macrophage. ${ }^{49}$ Consistent with this study, we here demonstrated that Rip $1^{K 45 A / K 45 A}$ cells were significantly, but not completely, resistant to necroptotic stimulation by TNF/Smac/ZVAD (Figures $6 \mathrm{~d}$ and e; Supplementary Figure S7b). Interestingly, Rip $1^{\Delta / \Delta}$ cells were more resistant to necroptosis than Rip $1^{K 45 A / K 45 A}$ cells under certain conditions, suggesting that $\mathrm{RIP}^{\Delta}{ }^{\Delta}$ was a more effective kinase-dead mutation than RIP1 ${ }^{\mathrm{K} 45 \mathrm{~A}}$ on blocking necroptosis signaling.

Prior studies reported that inhibiting RIP1 with Nec-1 or $\mathrm{RIP} 1^{\mathrm{KD}}$ mice did not ameliorate cerulein-induced pancreatitis. ${ }^{50,51}$ We found that the RIP1 P-loop deficiency also did not ameliorate cerulein-induced pancreatitis. In contrast to Newton et al. reports, ${ }^{51}$ our study showed that Rip3 $^{-/}$protected mice from cerulein-induced pancreatitis (Figures $4 \mathrm{a}$ and b). We speculate that the differences in colony microflora between particular animal facilities may account for these controversial results.

Previous reports have shown that RIP1 promoted TNFRmediated lethality at E10.5 in animals lacking Fadd or Caspase-8. ${ }^{29}$ Deletion of Rip1 could prevent embryonic lethality of Fadd- or Caspase-8 deficient mice. ${ }^{28,29,36}$ Our genetic study clearly demonstrated that distinct RIP1 kinasedead mutations acted differently on embryonic development of 
Fadd $^{-/}$mice. RIP1 ${ }^{\mathrm{K} 45 \mathrm{~A}}$ had little effect on the lethality of Fadd deficiency (Figures $1 \mathrm{a}-\mathrm{c}$ ), while $\mathrm{RIP} 1^{\Delta}$ could rescue the embryonic lethality of Fadd deficiency at E10.5 and Fadd ${ }^{--}$Rip $^{\Delta / \Delta}$ mice eventually died at E16.5 (Figures $5 a$ and b). One possible explanation for this apparent paradox is that the deficiencies of RIP1 kinase activity are different between RIP1 ${ }^{\mathrm{K} 45 \mathrm{~A}}$ and $\mathrm{RIP}^{\Delta}{ }^{\Delta}$. Comparing to $\mathrm{RIP}^{\Delta}{ }^{\Delta}$, the relatively high remaining RIP1 activity in RIP1 ${ }^{\mathrm{K} 45 \mathrm{~A}}$ may be responsible for the failure in rescue of the lethality of FADD-deficient mice at E10.5. Given that $\mathrm{RIP1} 1^{\mathrm{D} 138 \mathrm{~N}}$ also showed resistance to necroptosis triggered by various stimulations in vitro or in vivo, ${ }^{27}$ the function of RIP1 $1^{\mathrm{D} 138 \mathrm{~N}}$ on $\mathrm{Fadd}^{-/}$embryonic development needs to be further investigated.

Although RIP1 ${ }^{\Delta}$ could rescue the embryonic lethality of Fadd deficiency at E10.5, Fadd $^{/-}$Rip $1^{\Delta / \Delta}$ embryos died around E16.5. This lethality at E16.5 might be mediated by other signaling independent of RIP1 kinase activity. However, there may be another possibility that all RIP1 kinase-dead mutants including RIP1 ${ }^{\mathrm{K} 45 \mathrm{~A}}, \mathrm{RIP} 1^{\mathrm{D} 138 \mathrm{~N}}$ and $\mathrm{RIP} 1^{\Delta}$ may not thoroughly inactivate RIP1 kinase activity, and the remaining activity may have been sufficient to mediate the lethality of Fadd- or Casp8-deficient embryos at E16.5. Thus, it is necessary to explore the roles of RIP3 or MLKL in Fadd $^{-1}$ Rip $^{\Delta / \Delta}$ embryonic lethality by deletion of Rip3 or Mlkl in the future.

In summary, we identified a novel RIP1 kinase-dead mutant by altering the P-loop in kinase domain of RIP1, and subsequent genetic studies demonstrated that distinct kinase-dead mutations had different impacts on the embryonic development of $\mathrm{Fadd}^{-/}$mice. The distinct differences between various mutants might depend on their extents of resistance to necroptosis signaling. Thus, the roles of kinase activity of RIP1 on Fadd-deficient embryos need to be further clarified by other kinase defective mutants or via various genetic combinations. Our findings also implicate that RIP1 kinase activity, as an attractive target for treatments of diseases, needs to be clarified for developing specific inhibitors to treat disease.

\section{Materials and Methods}

Reagents. TNF- $\alpha$ and $z-V A D$ were purchased from R\&D (Minneapolis, MN, USA) and Calbiochem (Anaheim, CA, USA), respectively. The Smac mimetic, Cycloheximide and LPS were obtained from Sigma. Nec-1 was from Enzo Life Science (Alexis, USA). The following antibodies were used for western blotting: p-IkBa (Cell Signaling), p-ERK (Cell Signaling Technology, Danvers, MA, USA), ERK (Cell Signaling), p-P38 (Cell Signaling), P38 (Cell Signaling), p-P65 (Cell Signaling), p-JNK (Cell Signaling), JNK (Cell Signaling), PARP (Cell Signaling), Caspase-3 (Cell Signaling), HA (Cell Signaling), Caspase-8 (Enzo Life Science), RIP1 (BD Biosciences, Franklin Lakes, NJ, USA), p-RIP1(S166) (Cell Signaling) mouse RIP3 (ProSci, San Diego, CA, USA), MLKL (Abcam, Cambridge, UK), p-MLKL (Abcam), $\beta$-actin, $\alpha$-Tubulin and anti-flag-HRP (Sigma). Anti-phospho-RIP3 antibody (mouse) was generated in our lab and immunoaffinity-purified. Cell viability was determined by measuring ATP levels using Cell Titer-Glo kit (Promega, Madison, WI, USA).

Mice. Mice were housed in a specific pathogen-free facility, which belongs to Institute for Nutritional Sciences. Fadd ${ }^{-/}$mice (C57BL/6) were gifted by Dr. Jianke Zhang (Thomas Jefferson University, Philadelphia, USA), and Rip3 ${ }^{--}$mice (C57BL/6) were provided by Dr. Xiaodong Wang (NIBS, Beijing, China). Animals were subsequently backcrossed on a C57BL/6 background for at least 10 generations. A novel mutant, $\mathrm{RIP}^{\Delta}{ }^{\Delta}$, was obtained from the experiment with two amino acids $\mathrm{G}_{26} \mathrm{~F}_{27}$ in the P-loop of RIP1 deleted. To generate Rip $1^{\Delta / \Delta}$,
Rip $^{\text {K45A/K45A }}$, Rip $1^{-/-}$mice by crispr-cas9 mutation system (Bioray Laboratories Inc., Shanghai, China), different sgRNA were designed to target RIP1 kinase domain. (Rip $1^{1 / \Delta}$ mutant with gRNA: 5'-GACCTAGACAGCGGAGGCTT-3'; Rip $1^{\text {K45A/K45A }}$ mutant with gRNA: $5^{\prime}$-GCCCTGTGTATACTTTTTTC-3'; Rip $1^{-1-}$ with gRNA: $5^{\prime}$-GATGGCATCCAGTGACCTGC-3'). Additional information is provided upon request. All mutant mice and WT mice used in these studies shared a common genetic C57BL/6 background. Animal experiments were conducted in accordance with the guidelines of the Institutional Animal Care and Use Committee of the Institute for Nutritional Sciences, Shanghai Institutes for Biological Sciences, Chinese Academy of Sciences (CAS), University of Chinese Academy of Sciences.

Cerulein-induced acute pancreatitis. Male WT, Rip ${ }^{-/-}$and Rip $1^{\Delta / \Delta}$ mice littermates at 8 weeks of age $(n=7)$ were treated every hour for 12 consecutive hours with cerulein ( $50 \mu \mathrm{g} / \mathrm{kg}$, Sigma) intraperitoneal injection. Animals were assayed $24 \mathrm{~h}$ after the first injection. Serum amylase activity was assayed by amylase activity assay kit (Sigma).

Isolation and culture of MDFs, MEFs, BMDMs and thymocytes. MDFs were separated from the skin of newborn mice, and MEFs were isolated from E13.5 to E14.5 embryos. MDFs and MEFs were cultured in DMEM medium supplemented with $10 \% \mathrm{FBS}$ and penicillin/streptomycin. BMDMs from isolated bone marrow cells collected from mouse femurs and tibias were induced to differentiate in vitro. Bone marrow cells were cultured for 7 days in RPMI medium containing $10 \% \mathrm{FBS}$, penicillin/streptomycin and $50 \mathrm{ng} / \mathrm{ml} \mathrm{M}-\mathrm{CSF}$, and medium was changed every 2 days. Thymocytes were isolated from thymus and cultured in RPMI medium containing $10 \% \mathrm{FBS}$, penicillin/streptomycin and $50 \mu \mathrm{M} \beta$-ME.

Immunoblotting and immunoprecipitation. Cells were harvested at different time points, washed with PBS and lysates with $1 \times$ SDS sample buffer containing $100 \mathrm{mM}$ DTT and boiled for $5 \mathrm{~min}$ at $95^{\circ} \mathrm{C}$ for reducing gel. For mouse tissue protein extraction, E14.5 fetal liver and other tissues were ground by pestle and mortar with liquid $\mathrm{N}_{2}$, and the protein was extracted with RIPA lysis buffer. The lysates were cleared by centrifugation for $20 \mathrm{~min}$ at $13200 \times \mathrm{g}$, quantified by BCA kit (Thermo Scientific, Rockford, IL, USA) then mixed with SDS sample buffer and boiled at $95^{\circ} \mathrm{C}$ for $5 \mathrm{~min}$. The samples were separated using SDS-PAGE, transferred to PVDF membrane (Millipore, Darmstadt, Germany) with $100 \mathrm{v}$ for $2 \mathrm{~h}$. The proteins were detected by using a chemiluminescent substrate (Thermo Scientific). To immunoprecipitate RIP1, cell extract protein was incubated for $3 \mathrm{~h}$ with $5 \mu$ l of RIP1 antibody (BD Biosciences). After mixing end over end for overnight $\left(4{ }^{\circ} \mathrm{C}\right)$ with $30 \mu \mathrm{l}$ of G-Agarose beads, the agarose was collected and washed three times with cell lysis buffer (Tris-HCl $20 \mathrm{mmol} / \mathrm{l}(\mathrm{pH} 7.5), \mathrm{NaCl} 150 \mathrm{mM}$, EDTA $1 \mathrm{mM}$, EGTA $1 \mathrm{mM}$, Triton X-100 1\%, Sodium pyrophosphate $2.5 \mathrm{mM}, \beta$-Glycerrophosphate $1 \mathrm{mM}, \mathrm{NaVO}_{4} 1 \mathrm{mM}$, Leupeptin $1 \mu \mathrm{g} / \mathrm{ml}$.). Immunoprecipitates were denatured in SDS, subjected to SDS-PAGE, and immunoblotted.

RIP3 and MLKL oligomerization detection. The cells were cultured in six-well plates and treated with indicated stimuli. Cells were harvested at different time points and lysed with $2 \times$ DTT-free sample buffer (Tris-Cl (PH 6.8) $125 \mathrm{mM}$, SDS $4 \%$, Glycerol $20 \%$, Bromophenol blue $0.02 \%$ ) immediately. Total cell lysates were separated using SDS-PAGE, and transferred to PVDF membrane (Millipore), and western blotting was performed with RIP3 or MLKL antibodies.

Flow cytometry. Antibodies against mouse CD3, CD4, CD8, CD19, Mac-1 and Gr-1 from eBioscience (Carlsbad, CA, USA) were fluorescence-conjugated and were used for flow cytometry analysis in this study. We prepared single-cell suspension from lymph nodes, spleen and thymus, respectively, and stained them with fluorescence-conjugated antibodies for half an hour in staining buffer. After staining, cells were immediately analyzed by flow cytometry (FACSAria III, BD Biosciences).

Immunofluorescence. MDFs were plated overnight on coverslips before various stimulations. After stimulation, cells were washed with PBS and fixed with 4\% PFA in PBS for 15 min. Next, the cells were blocked with $0.3 \%$ Triton X-100 and $5 \%$ normal donkey serum (Jackson immunoResearch, Baltimore Pike, West Grove, $\mathrm{PA}$, USA) for $1 \mathrm{~h}$ at room temperature, then followed by first antibody incubation at $4{ }^{\circ} \mathrm{C}$ for overnight. Signals were developed with Alexa fluorescence antibodies (Invitrogen). Finally, the cells were stained with DAPI for $10 \mathrm{~min}$. Confocal microscopy analysis was performed using a Zeiss 710 laser-scanning microscope (Zeiss, Thornwood, NY, USA). 
RT-PCR. Total RNA was extracted using Trizol reagent (Life Technologies), according to the manufacturer's instructions. After quantification, $2 \mu \mathrm{g}$ total RNA was reverse transcribed to complementary DNA (Takara, Dalian, China). Transcript levels of indicated cytokines were quantified by quantitative RT-PCR on an ABI 7500 real-time PCR instrument with SYBR Green. Relative expression was calculated using LC32 as an internal control as indicated. Primers used were as follows: mIL-1b: 5'-CCCAACTGGTACATCAGCAC- $3^{\prime}$ and $5^{\prime}$-TCTGCTCATTCACGAAAAGG -3'; mTNF: 5'-CCCACTCTGACCCCTTTACT-3' and 5'-TTTGAGTCCTTGATGGT GGT-3'; mIL-6: 5'-CGGAGAGGAGACTTCACAGA-3' and 5'-CCAGTTTGG TAGCATCCATC-3'; mCXCL-1: 5'-CTGGGATTCACCTCAAGAACATC-3' and $5^{\prime}$ CAGGGTCAAGGCAAGCCTC-3'; mMCP-1: 5'-TTAAAAACCTGGATCGGAACCAA $-3^{\prime}$ and $5^{\prime}$-GCATTAGCTTCAGATTTACGGGT-3'; mCCL-5:5'-GCTGCTTTGCCTAC CTCTCC-3' and 5'-TCGAGTGACAAACACGACTGC- $3^{\prime}$.

\section{Conflict of Interest}

The authors declare no conflict of interest.

Acknowledgements. We thank $\operatorname{Dr}$ Xiaodong Wang (National Institute of Biological Sciences, Beijing, China) for providing Ripk3 ${ }^{-/-}$mice and Dr. Jianke Zhang (Thomas Jefferson University, Philadelphia, PA, USA) for providing Fadd ${ }^{+/}$mice. We also thank Dr Yu Sun (David Geffen School of Medicine, UCLA, USA) for insightful discussions and critical reading of the manuscript. This work was supported by grants from the National Natural Science Foundation of China (31571426) and the Ministry of Science and Technology of the People's Republic of China (2016YFC1304900, 2016YFA0500100). HBZ was supported by Thousand Young Talents Program of the Chinese government.

1. Stanger BZ, Leder P, Lee TH, Kim E, Seed B. RIP: a novel protein containing a death domain that interacts with Fas/APO-1 (CD95) in yeast and causes cell death. Cell 1995; 81 513-523.

2. Hsu H, Xiong J, Goeddel DV. The TNF receptor 1-associated protein TRADD signals cell death and NF-kappa B activation. Cell 1995; 81: 495-504.

3. Festjens N, Vanden Berghe T, Cornelis S, Vandenabeele P. RIP1, a kinase on the crossroads of a cell's decision to live or die. Cell Death Differ 2007; 14: 400-410.

4. Christofferson DE, Li Y, Yuan J. Control of life-or-death decisions by RIP1 kinase. Annu Rev Physiol 2014; 76: 129-150.

5. Hsu H, Huang J, Shu HB, Baichwal V, Goeddel DV. TNF-dependent recruitment of the protein kinase RIP to the TNF receptor-1 signaling complex. Immunity 1996; 4: 387-396.

6. Hsu H, Shu HB, Pan MG, Goeddel DV. TRADD-TRAF2 and TRADD-FADD interactions define two distinct TNF receptor 1 signal transduction pathways. Cell 1996; 84: 299-308.

7. Vince JE, Pantaki D, Feltham R, Mace PD, Cordier SM, Schmukle AC et al. TRAF2 must bind to cellular inhibitors of apoptosis for tumor necrosis factor (tnf) to efficiently activate nf-\{kappa\}b and to prevent tnf-induced apoptosis. J Biol Chem 2009; 2284: 35906-35915.

8. Ting AT, Pimentel-Muinos FX, Seed B. RIP mediates tumor necrosis factor receptor 1 activation of NF-kappaB but not Fas/APO-1-initiated apoptosis. EMBO J 1996; 15: $6189-6196$.

9. Gentle IE, Wong WW, Evans JM, Bankovacki A, Cook WD, Khan NR et al. In TNF-stimulated cells, RIPK1 promotes cell survival by stabilizing TRAF2 and cIAP1, which limits induction of non-canonical NF-kappaB and activation of caspase-8. J Biol Chem 2011; 286: 13282-13291.

10. Lin Y, Devin A, Rodriguez Y, Liu ZG. Cleavage of the death domain kinase RIP by caspase-8 prompts TNF-induced apoptosis. Genes Dev 1999; 13: 2514-2526.

11. Gerlach B, Cordier SM, Schmukle AC, Emmerich CH, Rieser E, Haas TL et al. Linear ubiquitination prevents inflammation and regulates immune signalling. Nature 2011; 471: 591-596.

12. Lee TH, Shank J, Cusson N, Kelliher MA. The kinase activity of Rip1 is not required for tumor necrosis factor-alpha-induced IkappaB kinase or P38 MAP kinase activation or for the ubiquitination of Rip1 by Traf2. J Biol Chem 2004; 279: 33185-33191.

13. Vanden Berghe $T$, Linkermann $A$, Jouan-Lanhouet $S$, Walczak $H$, Vandenabeele $P$. Regulated necrosis: the expanding network of non-apoptotic cell death pathways. Nat Rev Mol Cell Biol 2014; 15: 135-147.

14. Micheau O, Tschopp J. Induction of TNF receptor I-mediated apoptosis via two sequentia signaling complexes. Cell 2003; 114: 181-190.

15. Wang CY, Mayo MW, Baldwin AS Jr. TNF- and cancer therapy-induced apoptosis: potentiation by inhibition of NF-kappaB. Science 1996; 274: 784-787.

16. Chen ZJ. Ubiquitination in signaling to and activation of IKK. Immunol Rev 2012; 246 95-106.

17. Cho YS, Challa S, Moquin D, Genga R, Ray TD, Guildford M et al. Phosphorylation-driven assembly of the RIP1-RIP3 complex regulates programmed necrosis and virus-induced inflammation. Cell 2009; 137: 1112-1123.
18. He S, Wang L, Miao L, Wang T, Du F, Zhao L et al. Receptor interacting protein kinase-3 determines cellular necrotic response to TNF-alpha. Cell 2009; 137: 1100-1111.

19. Christofferson DE, Yuan J. Necroptosis as an alternative form of programmed cell death. Curr Opin Cell Biol 2010; 22: 263-268.

20. Degterev A, Hitomi J, Germscheid M, Ch'en IL, Korkina O, Teng X et al. Identification of RIP1 kinase as a specific cellular target of necrostatins. Nat Chem Biol 2008; 4: 313-321.

21. Bertrand MJ, Milutinovic S, Dickson KM, Ho WC, Boudreault A, Durkin J et al. ClAP1 and clAP2 facilitate cancer cell survival by functioning as E3 ligases that promote RIP1 ubiquitination. Mol Cell 2008; 30: 689-700.

22. Gaither A, Porter D, Yao Y, Borawski J, Yang G, Donovan J et al. A Smac mimetic rescue screen reveals roles for inhibitor of apoptosis proteins in tumor necrosis factor-alpha signaling. Cancer Res 2007; 67: 11493-11498.

23. Darding M, Feltham R, Tenev T, Bianchi K, Benetatos C, Silke J et al. Molecular determinants of Smac mimetic induced degradation of cIAP1 and cIAP2. Cell Death Differ 2011; 18: $1376-1386$.

24. Christofferson DE, Li Y, Hitomi J, Zhou W, Upperman C, Zhu H et al. A novel role for RIP1 kinase in mediating TNFalpha production. Cell Death Dis 2012; 3: e320.

25. Xie T, Peng W, Liu Y, Yan C, Maki J, Degterev A et al. Structural basis of RIP1 inhibition by necrostatins. Structure 2013; 21: 493-499.

26. Berger SB, Kasparcova V, Hoffman S, Swift B, Dare L, Schaeffer M et al. Cutting edge: RIP1 kinase activity is dispensable for normal development but is a key regulator of inflammation in SHARPIN-deficient mice. J Immunol 2014; 192: 5476-5480.

27. Polykratis A, Hermance N, Zelic M, Roderick J, Kim C, Van TM et al. Cutting edge: RIPK1 kinase inactive mice are viable and protected from TNF-induced necroptosis in vivo. J Immunol 2014; 193: 1539-1543.

28. Rickard JA, O'Donnell JA, Evans JM, Lalaoui N, Poh AR, Rogers T et al. RIPK1 regulates RIPK3-MLKL-driven systemic inflammation and emergency hematopoiesis. Cell 2014; 157: $1175-1188$.

29. Dillon CP, Weinlich R, Rodriguez DA, Cripps JG, Quarato G, Gurung P et al. RIPK1 blocks early postnatal lethality mediated by caspase-8 and RIPK3. Cell 2014; 157: 1189-1202.

30. Kelliher MA, Grimm S, Ishida Y, Kuo F, Stanger BZ, Leder P et al. The death domain kinase RIP mediates the TNF-induced NF-kappaB signal. Immunity 1998; 8: 297-303.

31. Zhang X, Fan $C$, Zhang H, Zhao Q, Liu Y, Xu C et al. MLKL and FADD are critical for suppressing progressive lymphoproliferative disease and activating the NLRP3 inflammasome. Cell Rep 2016; 16: 3247-3259.

32. Alvarez-Diaz S, Dillon CP, Lalaoui N, Tanzer MC, Rodriguez DA, Lin A et al. The pseudokinase MLKL and the kinase RIPK3 have distinct roles in autoimmune disease caused by loss of death-receptor-induced apoptosis. Immunity 2016; 45: 513-526.

33. Zhang H, Zhou X, McQuade T, Li J, Chan FK, Zhang J et al. Functional complementation between FADD and RIP1 in embryos and lymphocytes. Nature 2011; 471: 373-376.

34. Kaiser WJ, Upton JW, Long AB, Livingston-Rosanoff D, Daley-Bauer LP, Hakem R et al. RIP3 mediates the embryonic lethality of caspase-8-deficient mice. Nature 2011; 471: 368-372.

35. Oberst A, Dillon CP, Weinlich R, McCormick LL, Fitzgerald P, Pop C et al. Catalytic activity of the caspase-8-FLIP(L) complex inhibits RIPK3-dependent necrosis. Nature 2011; 471: 363-367.

36. Kaiser WJ, Daley-Bauer LP, Thapa RJ, Mandal P, Berger SB, Huang C et al. RIP1 suppresses innate immune necrotic as well as apoptotic cell death during mammalian parturition. Proc Natl Acad Sci USA 2014; 111: 7753-7758.

37. Wu XN, Yang ZH, Wang XK, Zhang Y, Wan H, Song $Y$ et al. Distinct roles of RIP1-RIP3 hetero- and RIP3-RIP3 homo-interaction in mediating necroptosis. Cell Death Differ 2014; 21: $1709-1720$.

38. Rebsamen M, Heinz LX, Meylan E, Michallet MC, Schroder K, Hofmann K et al. DAI/ZBP1 recruits RIP1 and RIP3 through RIP homotypic interaction motifs to activate NF-kappaB. EMBO Rep 2009; 10: 916-922.

39. de Almagro MC, Vucic D. Necroptosis: pathway diversity and characteristics. Semin Cell Dev Biol 2015; 39: 56-62.

40. Zhang Y, Su SS, Zhao S, Yang Z, Zhong CQ, Chen X et al. RIP1 autophosphorylation is promoted by mitochondrial ROS and is essential for RIP3 recruitment into necrosome. Nat Commun 2017; 8: 14329

41. Galluzzi L, Vanden Berghe T, Vanlangenakker N, Buettner S, Eisenberg T, Vandenabeele P et al. Programmed necrosis from molecules to health and disease. Int Rev Cell Mol Biol 2011; 289: 1-35.

42. Li J, McQuade T, Siemer AB, Napetschnig J, Moriwaki K, Hsiao YS et al. The RIP1/RIP3 necrosome forms a functional amyloid signaling complex required for programmed necrosis. Cell 2012; 150: 339-350.

43. Zhao XM, Chen Z, Zhao JB, Zhang PP, Pu YF, Jiang SH et al. Hsp90 modulates the stability of MLKL and is required for TNF-induced necroptosis. Cell Death Dis 2016; 7: e2089.

44. Yoon S, Bogdanov K, Kovalenko A, Wallach D. Necroptosis is preceded by nuclear translocation of the signaling proteins that induce it. Cell Death Differ 2016; 23: 253-260.

45. Wu J, Huang Z, Ren J, Zhang Z, He P, Li Y et al. Mlkl knockout mice demonstrate the indispensable role of Mlkl in necroptosis. Cell Res 2013; 23: 994-1006.

46. Welz PS, Wullaert A, Vlantis K, Kondylis V, Fernandez-Majada V, Ermolaeva M et al. FADD prevents RIP3-mediated epithelial cell necrosis and chronic intestinal inflammation. Nature $2011 ; 477$ : 330-334 
47. Fan C, Pu W, Wu X, Zhang X, He L, Zhou B et al. Lack of FADD in Tie-2 expressing cells causes RIPK3-mediated embryonic lethality. Cell Death Dis 2016; 7: e2351.

48. Kang TB, Ben-Moshe T, Varfolomeev EE, Pewzner-Jung Y, Yogev N, Jurewicz A et al. Caspase-8 serves both apoptotic and nonapoptotic roles. J Immunol 2004; 173: 2976-2984.

49. Shutinoski B, Alturki NA, Rijal D, Bertin J, Gough PJ, Schlossmacher MG et al. K45A mutation of RIPK1 results in poor necroptosis and cytokine signaling in macrophages, which impacts inflammatory responses in vivo. Cell Death Differ 2016; 23: 1628-1637.
50. Linkermann A, Brasen JH, Himmerkus N, Liu S, Huber TB, Kunzendorf U et al. Rip1 (receptor-interacting protein kinase 1) mediates necroptosis and contributes to renal ischemia/reperfusion injury. Kidney Int 2012; 81: 751-761.

51. Newton K, Dugger DL, Maltzman A, Greve JM, Hedehus M, Martin-McNulty B et al. RIPK3 deficiency or catalytically inactive RIPK1 provides greater benefit than MLKL deficiency in mouse models of inflammation and tissue injury. Cell Death Differ 2016; 23: 1565-1576.

Supplementary Information accompanies this paper on Cell Death and Differentiation website (http://www.nature.com/cdd) 